\title{
EfFect of Processing of Wood Planning on Static AND DyNAMic WetTing ANGLE AdHeSiveS
}

\author{
Murco Obucina, Seid Hajdarevic \& Almir Akvic
}
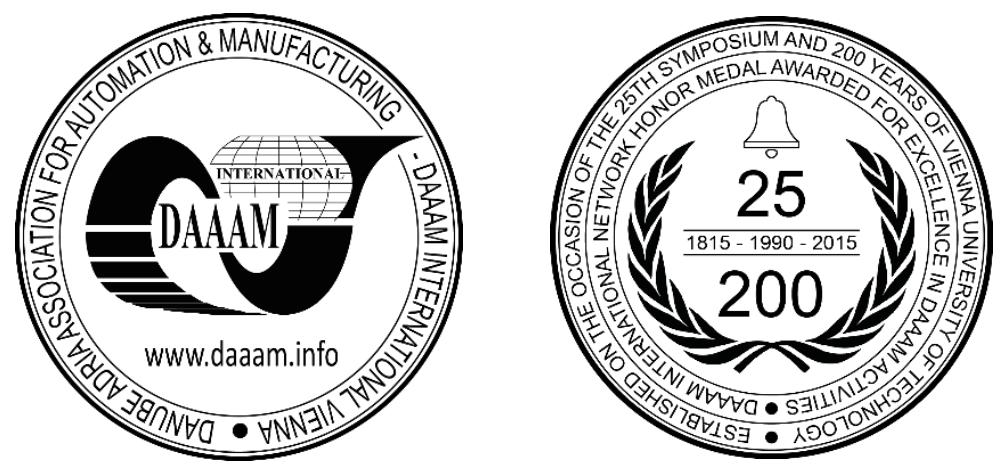

This Publication has to be referred as: Obucina, M[urco]; Hajdarevic, S[eid] \& Akvic, A[lmir] (2016). Effect of Processing of Wood Planning on Static and Dynamic Wetting Angle Adhesives, Proceedings of the 27th DAAAM International Symposium, pp.0131-0135, B. Katalinic (Ed.), Published by DAAAM International, ISBN 978-3-90273408-2, ISSN 1726-9679, Vienna, Austria

DOI: $10.2507 / 27$ th.daaam.proceedings.019

\begin{abstract}
The objective of this research was to study the effect of planning processing operations on the surface wettability of beech wood. For surface preparation were used two different machine types, Unimat 500 and Unimat Super 4. Quality parameters were monitored by surface roughness and the size of the wettability measured by estimated contact angle within the method of stationary droplet (sessile drop method) and dynamic wetting. Gluing was implemented with waterresistant PVAc adhesive, typically used for gluing massive wood. The results were statistically analyzed and compared with each other using the Student's t-Test.

There were no significant differences in surface roughness obtained by conventional planning and fig machine (sawing), although the processing of these two machines results in different types of surfaces. Slightly higher roughness was determined for planning processing. Established wetting angle is a significantly different, depending to the wood surface roughness and type of processing.
\end{abstract}

Keywords: Technology wood gluing; Surface roughness; Contact angle; Static wetting; Dynamic wetting

\section{Introduction}

Quality of solid wood panels gluing highly depends on the surface preparation. Planning, sawing (fig) machine are the two most common types of wood processing as preparation for applying the adhesive. Surface sanding may also be used, but it is uncommon type of technology for applying of glue on wood surface. Planning machine is used very often in technology of solid wood panels gluing, with its main disadvantage resulting in cycloid surface formed due to rotation of tool and simultaneous linear movement of work piece. Other processing type is machine with special circular saws tool often named fig machine.

Wood gluing takes a very important place in the wood technological processes. It significantly affects the market value and quality of wood products. Gluing is a complex process, during which several complex physicochemical processes takes place, due to the properties of wood and glue, their interactions and gluing technology. The main goal of gluing process is to achieve a combination of high strength and long-lasting strength, which in principle should not be less than the strength of the wood [2], [3], [5]. 
The strength of the bonded joint depends on several factors, the most on the adhesion, in addition to the properties of the adhesive. The adhesion of the glue-wood primarily depends on the wetting surface, glue penetration, porosity, $\mathrm{pH}$ value, moisture, surface tension, surface condition and anatomical directions of wood [4], [6]. Technological process of bonding and surface preparation of wood affects the quality of the shear strength, especially on the consistent quality of glued joint [5].

Bonding cannot be achieved without wetting surfaces to be bonded. Spreading of glue on the wood surface is the most important prerequisite for efficient and successful bonding. Wetting is in relation to surface tension and surface free energy of the system: hardwood body (wood)-glue-air [1], [7].

The wetting angle, as very important parameter, can be used to determine surface energy and adhesion. It has been found if adhesive angle is less than 90 degrees wood surface has good wetting - the lower wetting angle leads to better wetting. The optimal wetting is for surface where angle of wetting is close to zero degrees and in that case glue tends to be completely spread [4]. Based on research, it is recommended that the contact angle should be measured for volume greater than $0,1 \mathrm{ml}[8]$.

In this paper beech samples (Fagus sylvatica) were used for research of static and dynamic wetting angle, as well as roughness, by processing them on two different types of machines - planning and fig (sawing) machine.
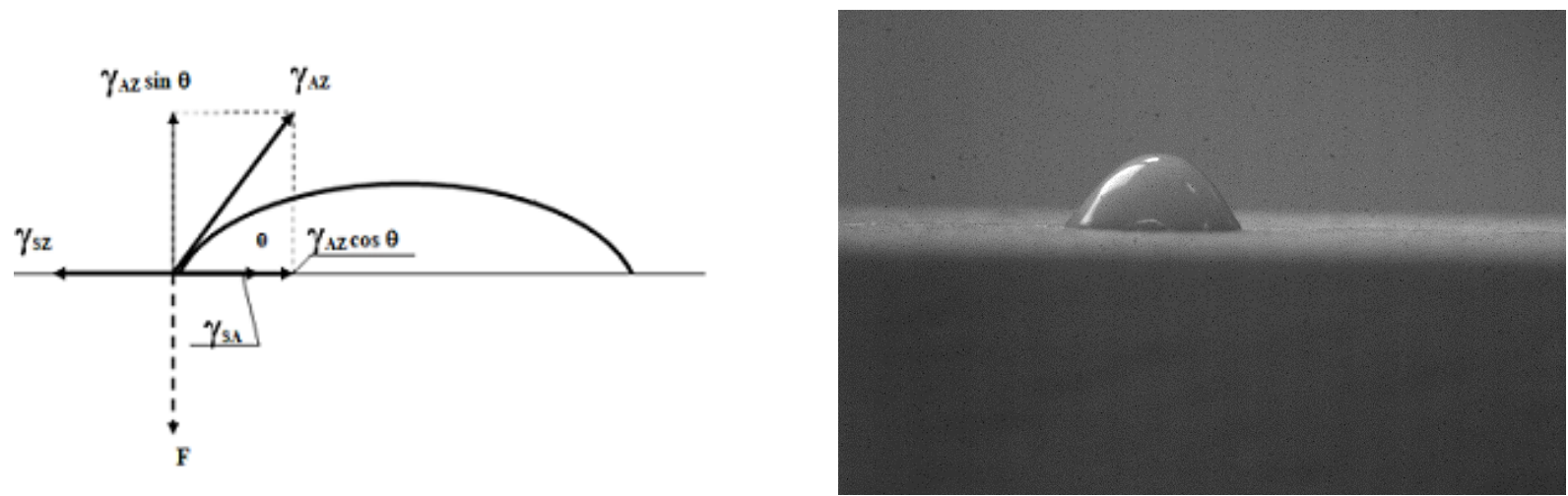

Fig. 1. Wetting angle of adhesive

\section{Methodology}

The first part of this research was to determine wood surface quality in "Laboratory of metal cutting and tools design" at Faculty of Mechanical Engineering Sarajevo University. Device "Mitutoyo SJ-201P Portable Surface Roughness Tester" was used for measuring of roughness, where the main point was on determining average length between the peaks and valleys and the deviation from the mean line on the entire surface within the sampling length (Ra) and vertical distance from the highest peak to the lowest valley $(\mathrm{Rz})$.

For measuring of static wetting angle simple dispenser was used. Through dispenser, droplets of the same size were discharged on wood surface. After a contact between droplet and wood surface had been made, the droplet started its spreading. The whole process was recorded with special PCO camera. Two hundred photos were saved between the moments of droplet discharge from dispenser until the moment of completely spreading. This process required patience and precision, as well as analysing those photos in software "Image J" with "drop analysis" plug-in, which allows precise measurement of the wetting angle. The purpose of this measuring was to compare wetting angles for beech samples, processed by conventional planning machine and fig machine, as well as to determine if there was significant difference between angles.
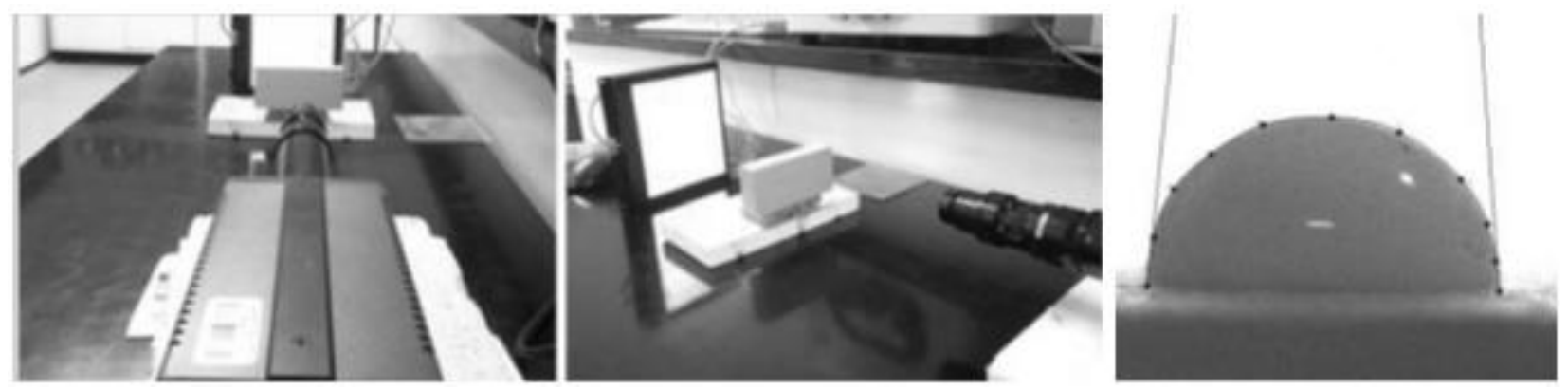

Fig. 2. PCO camera and wetting angle measuring by "ImageJ" software 
Dynamic wetting angle was testing by simulation of gluing in real production conditions. Practically, two glue droplets were discharged on wood surface sample by dispenser. There was space between two droplets, at the beginning of simulation, but droplets were close enough to become one after the end of process. That means the other wood sample was moving parallel to first wood piece and this was the simulation of real conditions of solid wood panels gluing. At the first phase, wood sample was moving down making partial contact with two droplets. Through phases 2 and 3 , wood sample was getting closer to the other sample. The final stage resulted in a full contact of wood samples.

Simulation of solid wood panels gluing was done by lowering one piece of wood sample to another by slim aluminium $1 \mathrm{~mm}$ thick pieces. Those aluminium sheets were made using the contact calibrator for metal. At the stage 1, there were 6 pieces on both sides of droplets, which resulted in $6 \mathrm{~mm}$ distance between wood samples. They have been pulling out from both sides simultaneously and the whole experiment was recorded by PCO camera that made 500 pictures in a second this time.
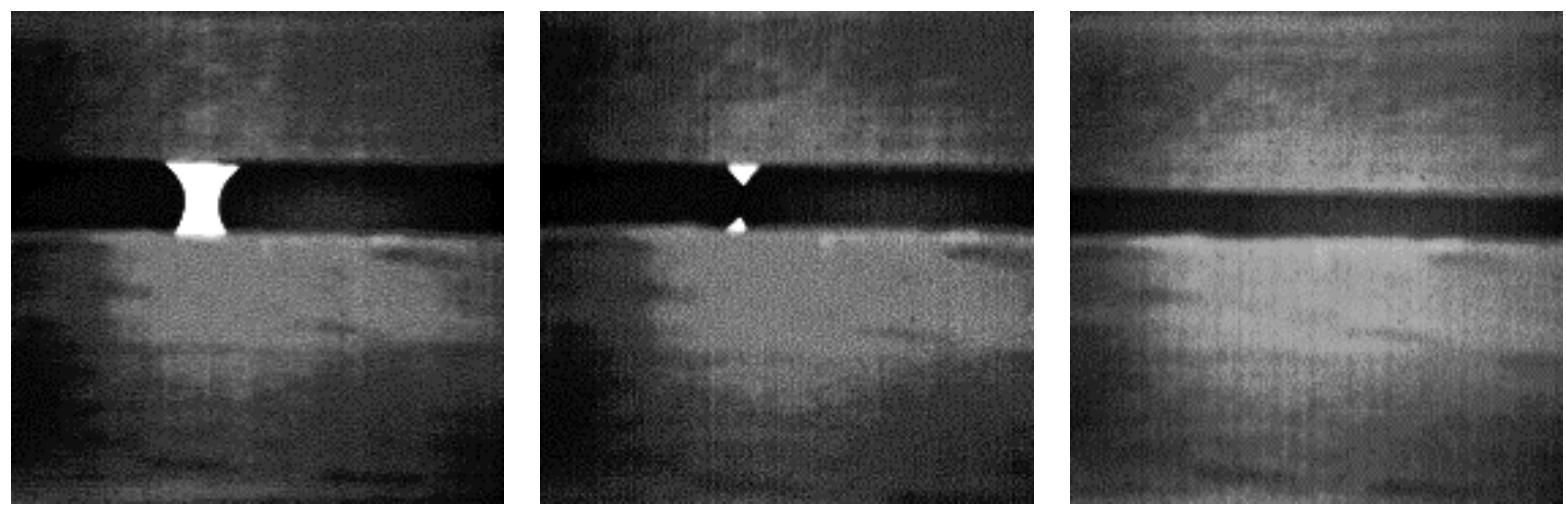

Fig. 3. PCO camera photos of simulation for measuring dynamic wetting angles Phases 2, 3 and 4

\section{Results}

By the end of roughness testing, all results have been processed and analysed. Statistical methods have been used, including Student's t-Tests as a part of data analysis of Microsoft Excel. The final results led to the conclusion there was no significant difference for wood samples earlier processed by planning machine, as well as fig (sawing) machine. Surface roughness still had higher value for samples processed by conventional planning machine (figure 4).

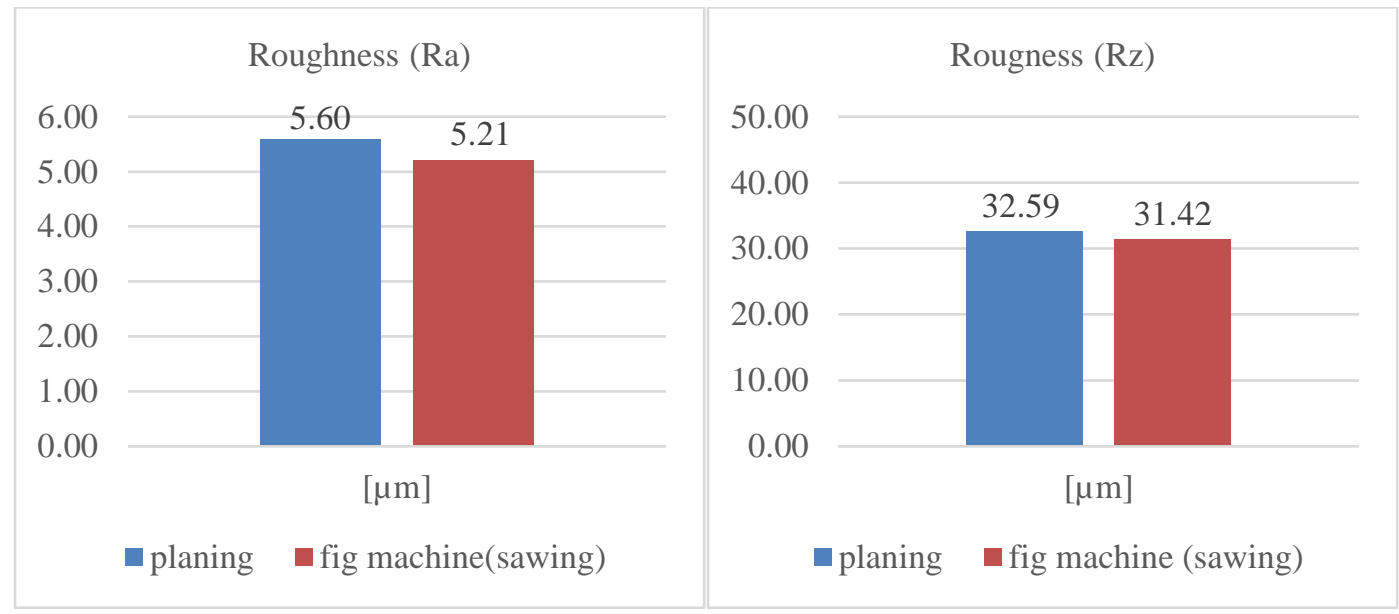

Fig. 4. Roughness measured for two types of processing

By comparing surface roughness for two types of wood processing, there was no significant difference and null hypothesis came to be true. Software "Image J" was used for editing of photos and measuring of wetting angle. Angle was measured from both sides of droplets, and arithmetic mean was used as the resulting angle. Data is presented in tables 1 and 2 and on figure 5.

As it is shown in charts above, static angle of wetting resulted in significant difference between variables. Wood samples processed by conventional planning method had significantly higher static angle value, in compare to wood samples processed by fig (sawing) machine. Null hypothesis was rejected, and alternative hypothesis came true, using the standard $\alpha=0.05$ cutoff. 


\begin{tabular}{|c|c|c|c|c|c|c|}
\hline \multirow{2}{*}{ No. } & \multicolumn{3}{|c|}{ PLANING MACHINE } & \multicolumn{3}{c|}{ FIG (SAWING) MACHINE } \\
\cline { 2 - 7 } & Left angle $\left[{ }^{\circ}\right]$ & Right angle $\left[{ }^{\circ}\right]$ & Mean $\left[{ }^{\circ}\right]$ & Left angle $\left[{ }^{\circ}\right]$ & Right angle $\left[{ }^{\circ}\right]$ & Mean $\left[{ }^{\circ}\right]$ \\
\hline 1 & 117 & 94 & 105,5 & 91 & 92 & 91,5 \\
\hline 2 & 103 & 98 & 100,5 & 82 & 85 & 83,5 \\
\hline 3 & 86 & 90 & 88 & 84 & 87 & 85,5 \\
\hline 4 & 87 & 92 & 89,5 & 87 & 87 & 87 \\
\hline 5 & 90 & 101 & 95,5 & 84 & 85 & 84,5 \\
\hline 6 & 85 & 59 & 72 & 88 & 83 & 85,5 \\
\hline 7 & 94 & 81 & 87,5 & 87 & 83 & 85 \\
\hline 8 & 94 & 96 & 95 & 84 & 94 & 89 \\
\hline 9 & 87 & 92 & 89,5 & 96 & 64 & 80 \\
\hline 10 & 97 & 100 & 98,5 & 80 & 87 & 83,5 \\
\hline
\end{tabular}

Table 1. Static angle full data

\begin{tabular}{|c|c|c|c|c|c|c|}
\hline & \multicolumn{3}{|c|}{ PLANING MACHINE } & \multicolumn{3}{|c|}{ FIG (SAWING) MACHINE } \\
\hline & Left angle $\left[{ }^{\circ}\right]$ & Right angle $\left[{ }^{\circ}\right]$ & Mean $\left[{ }^{\circ}\right]$ & Left angle $\left[{ }^{\circ}\right]$ & Right angle $\left[{ }^{\circ}\right]$ & Mean $\left[{ }^{\circ}\right]$ \\
\hline$\mu\left[{ }^{\circ}\right]$ & 94,00 & 90,30 & 92,15 & 86,30 & 84,70 & 85,50 \\
\hline St.dev. $\left[{ }^{\circ}\right]$ & 9,88 & 12,41 & 90,67 & 4,64 & 8,10 & 84,83 \\
\hline K.var. [\%] & 10,51 & 13,74 & 89,74 & 5,38 & 9,56 & 85,06 \\
\hline Min. $\left[{ }^{\circ}\right]$ & 85,00 & 59,00 & 90,04 & 80,00 & 64,00 & 84,98 \\
\hline $\operatorname{Max} .\left[^{\circ}\right]$ & 117,00 & 101,00 & 90,06 & 96,00 & 94,00 & 84,77 \\
\hline
\end{tabular}

Table 2. Static angle data

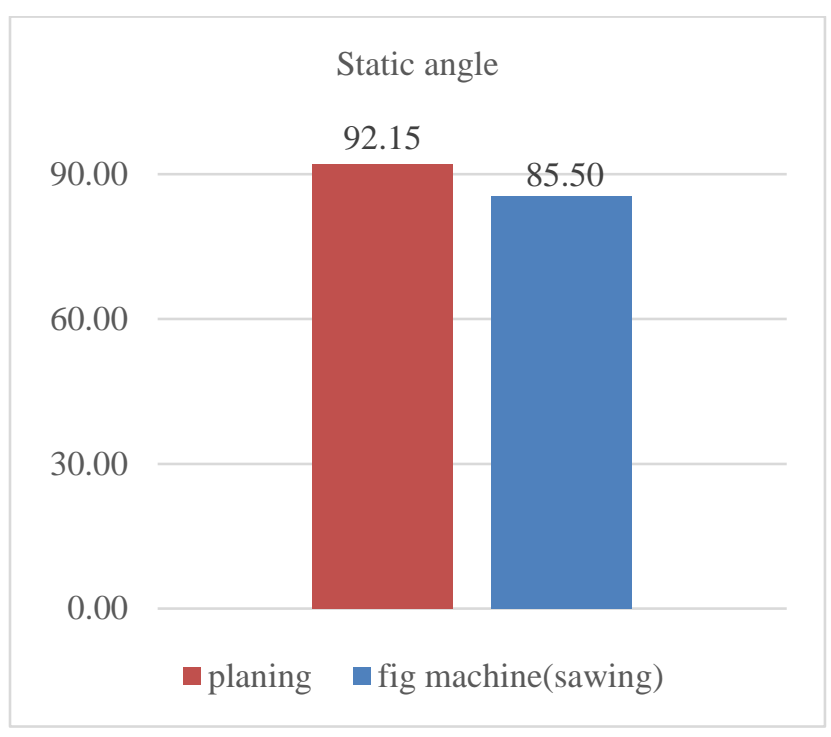

Fig. 5. Static angle measured for two types of processing

As the chart above shows it, static angle of wetting resulted in significant difference between variables. Wood samples processed by classic planing had significantly higher static angle value, in compare to wood samples processed by fig (sawing) machine. Null hypothesis was rejected and alternative hypothesis came true, using the standard $\alpha=0.05$ cut off.

Dynamic wetting angle made this research more interesting by simulating real gluing conditions of solid wood. Results for dynamic angle measuring are given in table 3 and charts 6.a. and 6.b.

\begin{tabular}{|c|c|c|c|c|}
\hline Phase No & Mean value $\left.\alpha{ }^{\circ}\right]$ & Mean value $\beta\left[^{\circ}\right]$ & Mean value $\gamma\left[{ }^{\circ}\right]$ & Mean value $\delta\left[{ }^{\circ}\right]$ \\
\hline 1 & 126.5 & 128.3 & 148 & 146 \\
\hline 2 & 131 & 131.6 & 152.5 & 156.5 \\
\hline 3 & 127 & 125.2 & 149 & 145 \\
\hline 4 & 134 & 134.4 & 122 & 137.5 \\
\hline
\end{tabular}

Table 3. Dynamic angle data 


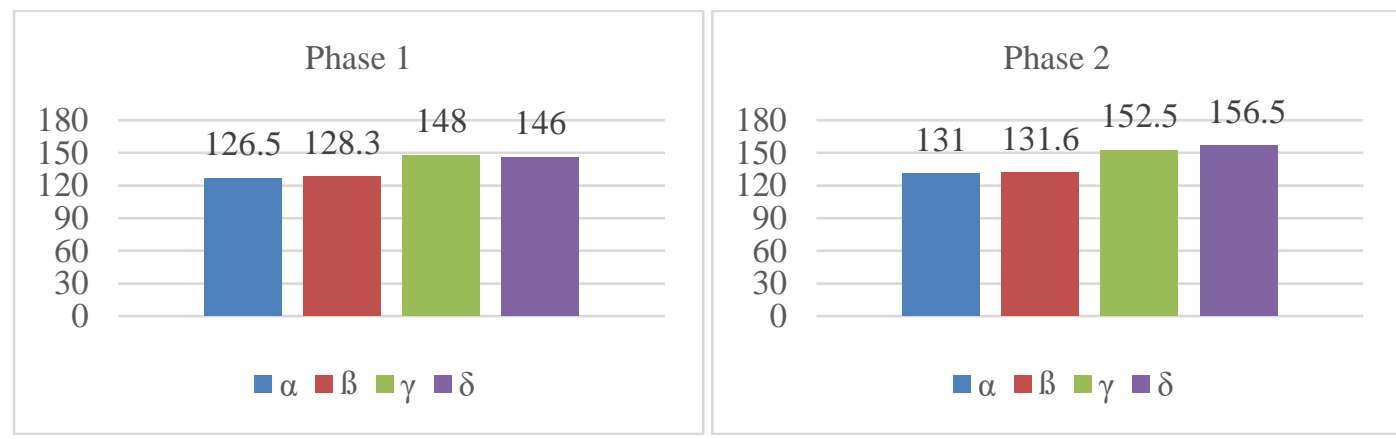

Fig. 6.a. Dynamic angle data measured in phases 1 and 2

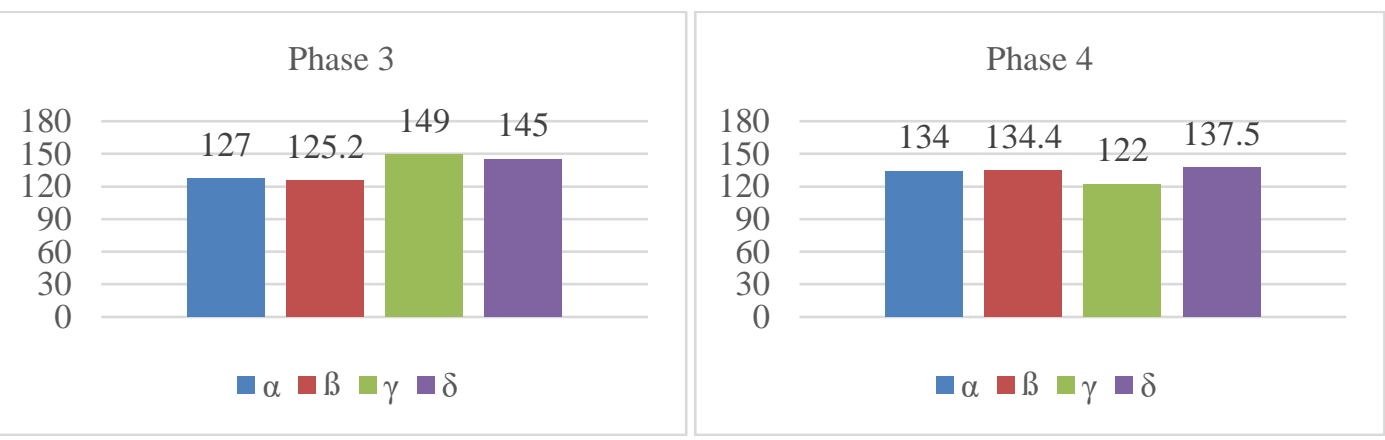

Fig. 6.b. Dynamic angle data measured in phases 3 and 4

In the future researches, wetting angles and both side adhesive penetration should be considered, as well as quality of gluing depending on these two factors.

\section{Conclusion}

Although processing on these machines resulted in different surface types and surface roughness, there was no significant difference by comparing surface roughness values for samples processed on conventional planning machine and fig (sawing) machine. For samples processed on planning machine surface roughness resulted in slightly higher values. In this paper static and dynamic angle were measured. By comparing static angle values for samples processed on planning and fig (sawing) machine, result sled to conclusion there was significant, but not highly significant difference. It is important to mention the coefficient of variation that resulted in lower values for samples processed on fig (sawing) machine. The conclusion for static angle of surface wetting, resulted in higher values for samples processed by conventional planning process, due to cycloid surface. Despite this conclusion, difference was not significant. Fig (sawing) machine processing sawing tools are parallel and that fact ensure, not only precise processing, but also optimally prepared surfaces for gluing. This is the reason why fig (sawing) machine is widely used in solid wood panel productions.

Dynamic wetting angle should be measured by proper mechanical simulator of gluing and that method could improve new knowledge about change of adhesive angles during solid wood panels gluing.

\section{References}

[1] Bogner, A.; Grbac, I.; Despot, R. (2002).Adhesion and Optimum Surface Tension of Adhesives, Wood Research 47

[2] Gindl, M.; Tschegg, S. (2002). Significance of the acidity of wood to the surface free energy components of different wood species, Langmuir, 18, 3209-3212

[3] Marra, A.A. (1992). Technology of wood bonding: principles in practice, Van Nostrand Reinhold, New York

[4] Obucina, M.; Gondzic, E.; Manso, E. The Influence of Adhesion Temperature to the Shear Strength of Width Glued Wooden Elements ". 25th International Symposium on Intelligent Manufacturing and Automation, DAAAM 2014. Procedia Engineering 100 (2015) 321-327

[5] Obucina M.; Akvic, A."Influence of gluing technology on the shear strength in the gluing of solid wood",Proceedings of the 26th DAAAM International Symposium,pp.0182-0188, B. Katalinic (Ed.), Published by DAAAM International, ISBN 978-3-902734-07-5, ISSN 1726-9679, Vienna, Austria DOI:10.2507/26th.daaam.proceedings.026

[6] I. Rowell; R, M. Chemical Modification of Wood for Improved adhesion in Composites, Wood Adhesives, Forest Products Society, Madison, (1996) WI., 69-78

[7] Sernek, M.; Resnik, J.; Kamke, F.A. (1999). Penetration of liquid urea-formaldehyde adhesive into beech wood, Wood and Fiber Sci. 31(1), 41-48

[8] McGuire, J; Yang, J. (1991). The effect of drop volume on contact angle, J. Food Protection, 54, 3, 232-235 